\section{REACTIVATING ANTITUMOR IMMUNITY IN GLIOMAS WITH OSTEOPONTIN/INTEGRIN BLOCKING PEPTIDE}

${ }^{1}$ Paulina Pilanc-Kudlek*, 'Katarzyna Poleszak, 'Aleksandra Ellert-Miklaszewska, ${ }^{1}$ AdriaJaume Roura Canalda, ${ }^{2}$ Salwador Cyranowski, 'Julian Swatler, 'Barttomiej Gielniewski, ${ }^{1}$ Bożena Kamińska. 'Nencki Institute of Experimental Biology, Polish Academy of Sciences, Warsaw, Poland, Warsaw, Poland; ${ }^{2}$ Postgraduate School of Molecular Medicine, Medical University of Warsaw, Warsaw, Poland, Warsaw, Poland

Background Glioblastoma (GBM) is the most common and aggressive primary brain tumor in adults. Despite improvements in imaging, surgical techniques, radiotherapy and chemotherapy, the prognosis of patients with GBM remains poor with a median overall survival of 15 months [1,2]. GBM is immunologically a "cold" tumor with low infiltration of functional $\mathrm{T}$ and NK cells, which imposes poor responsiveness of GBM patients to immunotherapies. The immunosuppressive microenvironment in GBM is created by the malignant cells and tumor-associated macrophages (TAMs), such as resident brain microglia and recruited peripheral myeloid cells [3]. Osteopontin/Spp1 is one of glioma-derived factors that is responsible for the protumorigenic reprogramming of TAMs [4]. SPP1 expression is highly elevated in tumor tissues and sera from GBM patients, and inversely correlates with patient survival [5]. Cross-talk between malignant cells and TAMs relays on osteopontin binding to integrin receptors (mainly $\alpha v \beta 3$ and $\alpha v \beta 5$ ) via its RGD motif [6]. Thus, with the use of a RGD peptide (our in-house designed competitor of binding to integrins) we interfered with glioma-microglia interaction in vitro and evaluated the in vivo antitumor efficacy of integrin blockade as a monotherapy and in combination with an immune check-point inhibitor.

Methods The efficacy of the RGD peptide to block microgliadependent glioma invasion was determined in a Matrigel invasion assay. Antitumor activity of the peptide was assessed in a murine syngeneic orthotopic GL261 glioma model. RGD peptide was administrated intratumorally via osmotic pomps. For combination therapy, the animals received anti-PD-1 or isotype IgG antibody (4 inj. x $10 \mathrm{mg} / \mathrm{kg}$ i.p.). Tumor volume was measured using MRI. Heterogeneity of the immune cells compartment of glioma microenvironment was analysed by flow cytometry. The transcriptomes of CD11b + cells immunosorted from tumor-bearing mouse brains were evaluated using RNAseq. Cytokine levels in the blood and the brain homogenates were measured using Luminex bead-based assays.

Results The microglia-stimulated invasion of GL261 glioma cells was reduced significantly in the presence of the RGD peptide in the in vitro co-culture system. The RGD peptide administrated to tumor-bearing mice induced proinflammatory reprogramming of TAMs. Combination of the RGD peptide with anti-PD-1 therapy increased the production of proinflammatory cytokines and the percentage of effector CD8+(CD44 +CD62L-) cells in the tumors.

Conclusions These results demonstrate that blockade of osteopontin/integrin signaling using the RGD peptide can mitigate the immunosuppressive microenvironment, reactivate the antitumor immunity and lay ground for improved response to immunotherapy in GBM.

\section{REFERENCES}

1. Jemal A, Murray T, Ward E, Samuels A, Tiwari RC, Ghafoor A, Feuer EJ, Thun MJ: Cancer statistics, 2005. CA Cancer J Clin 2005, 55(1):10-30.

2. Stupp R, Hegi ME, Mason WP, van den Bent MJ, Taphoorn MJ, Janzer RC, Ludwin SK, Allgeier A, Fisher B, Belanger $K$ et al: Effects of radiotherapy with concomitant and adjuvant temozolomide versus radiotherapy alone on survival in glioblastoma in a randomised phase III study: 5-year analysis of the EORTC- NCIC trial. Lancet Oncol 2009, 10(5):459-466.

3. Woroniecka KI, Rhodin KE, Chongsathidkiet P, Keith KA, Fecci PE: T-cell Dysfunction in Glioblastoma: Applying a New Framework. Clin Cancer Res 2018, 24 (16):3792-3802

4. Denhardt, D.T., M. Noda, A.W. O'Regan, D. Pavlin, and J.S. Berman. 2001. Osteopontin as a means to cope with environmental insults: regulation of inflammation, tissue remodeling, and cell survival. J Clin Invest 107:1055-1061.

5. Grassinger, J., D.N. Haylock, M.J. Storan, G.O. Haines, B. Williams, G.A. Whitty, et al. 2009. Thrombin-cleaved osteopontin regulates hemopoietic stem and progenitor cell functions through interactions with alpha9beta1 and alpha4beta1 integrins. Blood 114:49-59.

6. Anborgh, P.H., J.C. Mutrie, A.B. Tuck, and A.F. Chambers. 2010. Role of the metastasis-promoting protein osteopontin in the tumour microenvironment. Journal of cellular and molecular medicine 14:2037-2044

Ethics Approval All research protocols conformed to the Guidelines for the Care and Use of Laboratory Animals (European and national regulations 2010/63/UE September 22, 2010 and Dz. Urz. UE L276/20.10.2010, respectively). Animals were decapitated by a qualified researcher. The First Warsaw Local Ethics Committee for Animal Experimentation approved the study (approval no. 812/2019).

http://dx.doi.org/10.1136/jitc-2021-SITC2021.615 